\title{
Cyclic AMP Only Partially Mediates the Actions of Serotonin at Lobster Neuromuscular Junctions
}

\author{
Michael F. Goy and Edward A. Kravitz \\ Department of Neurobiology, Harvard Medical School, Boston, Massachusetts 02115
}

\begin{abstract}
Serotonin (5-HT) has multiple physiological actions at lobster neuromuscular junctions, including facilitation of transmitter release from nerve terminals and an increase in the tone and excitability of muscle fibers. These physiological effects of 5-HT are accompanied by a rise in intracellular levels of cAMP. We have used combined biochemical and physiological approaches to investigate whether cAMP directly mediates the physiological actions of the hormone. Based on the following lines of evidence, we conclude that the postsynaptic increase in muscle tone occurs independently of CAMP and that while the cyclic nucleotide does play a role in the facilitation of transmitter release by $5-\mathrm{HT}$, there is also a CAMP-independent component to this facilitation. (1) Agents that mimic the action of 5-HT on CAMP levels (forskolin, IBMX, SQ20009, 8-bromo CAMP) fail to mimic the postsynaptic actions of the amine. These agents do facilitate transmitter release, although none of them has as large an effect as does 5-HT. (2) When 5-HT is removed, presynaptic facilitation decays as the sum of 2 exponentials with very different time courses. The rate of the slower process is similar to the rate of breakdown of CAMP, while the faster process and the postsynaptic response decay significantly more rapidly. (3) IBMX retards the breakdown of CAMP and simultaneously retards the decay of the slower presynaptic process, with little or no effect on the other responses. (4) IBMX and forskolin potentiate the effect of 5-HT on CAMP levels and selectively enhance the slowly decaying presynaptic component with little or no effect on the other responses.
\end{abstract}

Serotonin (5-hydroxytryptamine; 5-HT), acting as a neurohormone, can modulate the physiological properties of many types of neurons and muscle cells (Twarog, 1960; Gerschenfeld and Paupardin-Tritsch, 1974; Weiss et al., 1978; Drummond et al., 1980; Aghajanian, 1981; Kandel and Schwartz, 1982; Kristan and Weeks, 1983; Kravitz et al., 1985; Richardson et al., 1985; Vanhoutte, 1985). We have been studying serotonergic modulation of neuromuscular transmission in the lobster, Homarus

\footnotetext{
Received Aug. 18, 1987; revised June 2, 1988; accepted June 3, 1988.

This work was supported by NIH Grants NS07848 (to E. A. K.) and NS21290 (to M. F. G.). We thank Kathleen Dunlap for reading and commenting on the manuscript. We are grateful to Michael Johnston and Peter Hess for computer software and for invaluable help with the computer analysis of data. Wendy Brooks provided cheerful and expert secretarial assistance and Mike LaFratta constructed several essential pieces of equipment.

Correspondence should be addressed to Edward A. Kravitz, Department of Neurobiology, Harvard Medical School, 220 Longwood Avenue, Boston, MA 02115 .

Present address: Department of Physiology, University of North Carolina, Chapel Hill, NC 27599.

Copyright (C) 1989 Society for Neuroscience $0270-6474 / 89 / 010369-11 \$ 02.00 / 0$
}

americanus, using the dactyl opener muscle from the animal's walking leg as an experimental system. Our goal is to understand the mechanisms that underlie synaptic modulation in this relatively simple, homogeneous tissue.

The anatomy and physiology of the preparation are well characterized. The muscle is innervated by 2 axons (Weirsma and Ripley, 1952), one excitatory, using glutamate as its transmitter (Kravitz et al., 1970; Kawagoe et al., 1982), and the other inhibitory, using gamma-amino butyrate (Takeuchi and Takeuchi, 1965; Otsuka et al., 1966). 5-HT, applied to isolated neuromuscular preparations, alters the properties of the nerve terminals and also of the muscle fibers that they innervate. The role of 5-HT seems to be to prime both nerve and muscle to function more vigorously, thereby enhancing synaptic transmission. The amine induces a 2- to 5-fold increase in release of transmitter from excitatory terminals (Grundfest and Reuben, 1961; Dudel, 1965; Kravitz et al., 1980; Glusman and Kravitz, 1982). This facilitation compriscs at least 2 components, distinguishable by their time courses (Glusman and Kravitz, 1982). Facilitation of transmitter release has also been observed in 5-HT-treated inhibitory terminals (Kravitz et al., 1980). In addition, muscle fibers become more excitable. They develop a sustained increase in tone when exposed to 5-HT, although no appreciable change in resting potential or input resistance is observed (Florey and Florey, 1954; Grundfest and Reuben, 1961; Battelle and Kravitz, 1978; Kravitz et al., 1980). If the muscle is depolarized following 5-HT application (for example by elevating extracellular $\mathrm{K}^{+}$or by activating the excitatory nerve), contraction is further enhanced; cells still maintain higher tension than depolarized control fibers (M. F. Goy and T. L. Schwarz, unpublished observations), and often show repetitive $\mathrm{Ca}^{2+}$-dependent action potentials (Kravitz et al., 1980). One mechanism underlying the physiological changes induced by 5-HT in muscle may be an increase in voltage-dependent inward current carried by $\mathrm{Ca}^{2+}$ ions, as suggested by voltage-clamp analysis (Kravitz et al., 1980).

5-HT is not found in detectable amounts in lobster exoskeletal muscle (Livingstone et al., 1981). However, it is widely distributed throughout the crustacean nervous system and, in particular, is found in high concentration in peripheral neurosecretory structures in close contact with the circulation (Florey and Florey, 1954; Maynard and Welsh, 1959; Welsh and Moorhead, 1960; Cooke and Goldstone, 1970; Livingstone et al., 1981; Beltz and Kravitz, 1983). Depolarization of these neurosecretory structures results in the $\mathrm{Ca}^{2+}$-dependent release of 5-HT (Sullivan et al., 1977; Sullivan, 1978; Livingstone et al., 1981), and it is therefore generally believed that the amine reaches peripheral targets (such as the exoskeletal muscles) via the hemolymph. This idea is supported by the observation that low 
levels of 5-HT can be measured in hemolymph withdrawn from living lobsters (Livingstone et al., 1980). In addition, the low threshold concentration for the action of 5-HT at neuromuscular junctions (between $10^{-8}$ and $10^{-9} \mathrm{M}$ ) is consistent with its suggested hormonal role in these tissues.

One biochemical mechanism that often has been implicated in the neurohormonal actions of 5-HT, especially in invertebrates, is cAMP-dependent protein phosphorylation. In lobster neuromuscular preparations, 5-HT elevates cAMP levels (Battelle and Kravit7, 1978) and thereby alters the state of phosphorylation of a 29,000 Da protein (Goy et al., 1984). It is not known, however, whether cyclic nucleotides are involved in any of the physiological changes induced by the hormone. In the studies reported here, we investigate this question using pharmacological agents to simultaneously perturb cyclic nucleotide metabolism and synaptic physiology. The results suggest that cAMP plays a direct role in the facilitation of transmitter release by 5 -HT but that there is also a cAMP-independent component to this facilitation. The postsynaptic changes in muscle tone induced by the amine do not appear to be directly mediated by cAMP.

\section{Materials and Methods}

Lobsters (Homarus americanus), weighing approximately $0.5 \mathrm{~kg}$, were purchased locally and held in artificial seawater (Instant Ocean, Aquarium Systems, Eastlake, $\mathrm{OH}$ ) at $12-14^{\circ} \mathrm{C}$. Walking legs were dissected in cold lobster saline ( $462 \mathrm{~mm} \mathrm{NaCl}, 16 \mathrm{~mm} \mathrm{KCl}, 26 \mathrm{~mm} \mathrm{CaCl}_{2}, 8 \mathrm{~mm}$ $\mathrm{MgCl}_{2}, 11 \mathrm{~mm}$ glucose, $10 \mathrm{~mm}$ Tris-maleate, $\mathrm{pH}$ 7.4). The dorsal surface of the dactyl opener muscle in the propopodite segment of the walking leg was exposed by removing overlying exoskeleton, muscle, sensory nerves, and connective tissue as described by Otsuka et al. (1966). For cAMP measurements, the bundle containing the nerves innervating the muscle was cut and removed at the point at which it contacts the surface of the muscle. For physiological experiments the intact nerve bundle was followed proximally into the adjacent segment of the leg (the carpopodite) and dissected free of other tissues.

Tension measurement and intracellular recording. Isolated neuromuscular preparations were superfused continuously with lobster saline at $12-14^{\circ} \mathrm{C}$ (approximately $3 \mathrm{ml} / \mathrm{min}$ ). To determine muscle tension, the distal end of the tendon was cut and fastened with silk thread to a Grass FT03 force transducer. For intracellular recording, muscle fibers were penetrated with 3-5 M $\Omega$ glass microelectrodes filled with $4 \mathrm{M}$ potassium acetate. Potential changes were recorded differentially between the microelectrode and the bath, grounded through a silver/silver chloride electrode. Force transducer and electrode outputs were amplified with high-impedance preamplifiers and recorded on magnetic tape (Hewlett-Packard 3968A Instrumentation Recorder). Tension recordings, evoked electrical responses (following stimulation of the excitatory nerve through a suction electrode, using $0.5-1 \mathrm{msec}$ square pulses), and miniature synaptic potentials (due to spontaneous release of transmitter from excitatory nerve terminals) were digitized and analyzed with the aid of a microcomputer.

To evaluate the decline in synaptic potential amplitude following washout of 5-HT, the best fit of the equation

$$
\text { amplitude }=c_{1} \exp \left(-t / \tau_{1}\right)+c_{2} \exp \left(-t / \tau_{2}\right)+c_{3}
$$

was determined by an iterative nonlinear curve-fitting program. The constants $(c)$ represent the mean amplitude of the synaptic potentials after the response has decayed completely $\left(c_{3}\right)$, and the contributions of the slowly decaying $\left(c_{2}\right)$ and rapidly decaying $\left(c_{1}\right)$ components. The constants $\tau_{2}$ and $\tau_{1}$ are the time constants for the slow and rapid processes, and $t$ is the time after washout of the amine.

Tension responses were quantitated either by measuring the area under the tension-time curve or by measuring the height of the maximum deflection from baseline tension. The former method was used when 2 5-HT responses were compared with each other (last column in Table 1). The latter method was used when the response induced by a pharmacological agent was compared to the response induced by $5-\mathrm{HT}$ (middle column in Table 1).

cAMP measurements. The cAMP content of neuromuscular prepa- rations was determined essentially as described previously (Goy et al., 1984). All experiments included a $2 \mathrm{hr}$ preincubation either in lobster saline or, where indicated, in $0.5 \mathrm{~mm}$ isobutyl methylxanthine (IBMX), followed by drug or hormone treatments as described in Results. At the end of the incubation period, the muscle was frozen in methanol at $-80^{\circ} \mathrm{C}$, cut free from the exoskeleton, and homogenized in $0.8 \mathrm{ml}$ of ice-cold $6 \%$ trichloroacetic acid (TCA). After $15 \mathrm{~min}$ at $4^{\circ} \mathrm{C}$ the homogenate was centrifuged for $5 \mathrm{sec}$ in a Beckman Microfuge. The pellet was washed with an additional $0.2 \mathrm{ml}$ of ice-cold $6 \% \mathrm{TCA}$, centrifuged, and the 2 TCA-soluble supernatant fractions were combined. The pellet was dissolved in $1.5 \mathrm{ml}$ of $1 \mathrm{~N} \mathrm{NaOH}$, and total protein was determined (Lowry et al., 1951). The combined supernatant fractions were extracted 4 times with $4 \mathrm{ml}$ of water-saturated ether, diluted in $0.05 \mathrm{M}$ sodium acetate ( $\mathrm{pH}$ 6.2), and analyzed for cyclic nucleotide content by radioimmunoassay (procedures and materials obtained from New England $\mathrm{Nu}$ clear).

Materials. Forskolin was obtained from Calbiochem; 5-HT creatinine sulfate and 8-bromo cAMP from Sigma; IBMX from Aldrich; and SQ20009 from Squibb. All other chemicals were reagent grade, obtained from commercial sources.

\section{Results}

\section{Physiological effects of $5-\mathrm{HT}$}

5-HT modulates both pre- and postsynaptic aspects of crustacean neuromuscular physiology. This has been well-documented in the American lobster, H. americanus (for a recent review, see Kravitz et al., 1985). Some typical effects of the amine on lobster physiology are illustrated in Figure 1. The prominent increase in muscle tone (Fig. 1c) represents an easily studied postsynaptic response. In addition, 5-HT induces an increase in the amplitude of excitatory junctional potentials (ejp's), as shown in Figure 1, $a, b$. This facilitation of synaptic potential size results from an increase in the number of quanta released when the action potential invades the terminal, rather than an increase in the sensitivity of the postsynaptic membrane (Dudel, 1965; Wheal and Kerkut, 1976; Glusman and Kravitz, 1982). Thus, the effects of 5-HT on ejp amplitude represent presynaptic actions of the amine. 5-HT also facilitates transmitter release from inhibitory nerve terminals (Kravitz et al., 1980). In this communication we have not analyzed the effects of 5-HT on inhibitory terminals, and all reference to presynaptic actions is concerned only with actions on excitatory terminals.

The pre- and postsynaptic responses to 5-HT are dose dependent. As seen in Figure 2, the threshold for both actions is between $10^{-9}$ and $3 \times 10^{-9} \mathrm{M}$ (see also Dudel, 1965; Kravitz et al., 1980; Glusman and Kravitz, 1982; Dixon and Atwood, 1985). The responses increase with increasing concentrations up to $10^{-6}-10^{-5} \mathrm{M}$, where they begin to saturate.

The actions of 5-HT on the preparation are relatively slow and long lasting compared with the actions of the excitatory and inhibitory transmitters. The postsynaptic response is typically of shorter duration than the presynaptic response and often begins to reverse even before the hormone has been washed out of the preparation. The presynaptic response is generally maintained with little or no decrement for as long as the 5-HT is present (up to $30 \mathrm{~min}$ ). Note that when $5-\mathrm{HT}$ is removed, the enhanced ejp amplitude decays in a markedly biphasic manner (Glusman and Kravitz, 1982; inset, Fig. $1 b$ ). This suggests that there are at least 2 distinguishable processes in excitatory nerve terminals that occur at different rates during washout. In 17 representative experiments taken from our current studies, $10^{-7}$ M 5-HT induced a $4.4 \pm 0.3$-fold increase in ejp amplitude (mean \pm SEM). The slowly decaying process accounted for 68.6 $\pm 4.2 \%$ of this increase (mean \pm SEM) and decayed with a time constant of $69.7 \pm 15.3$ min (mean \pm SEM), while the rapidly 

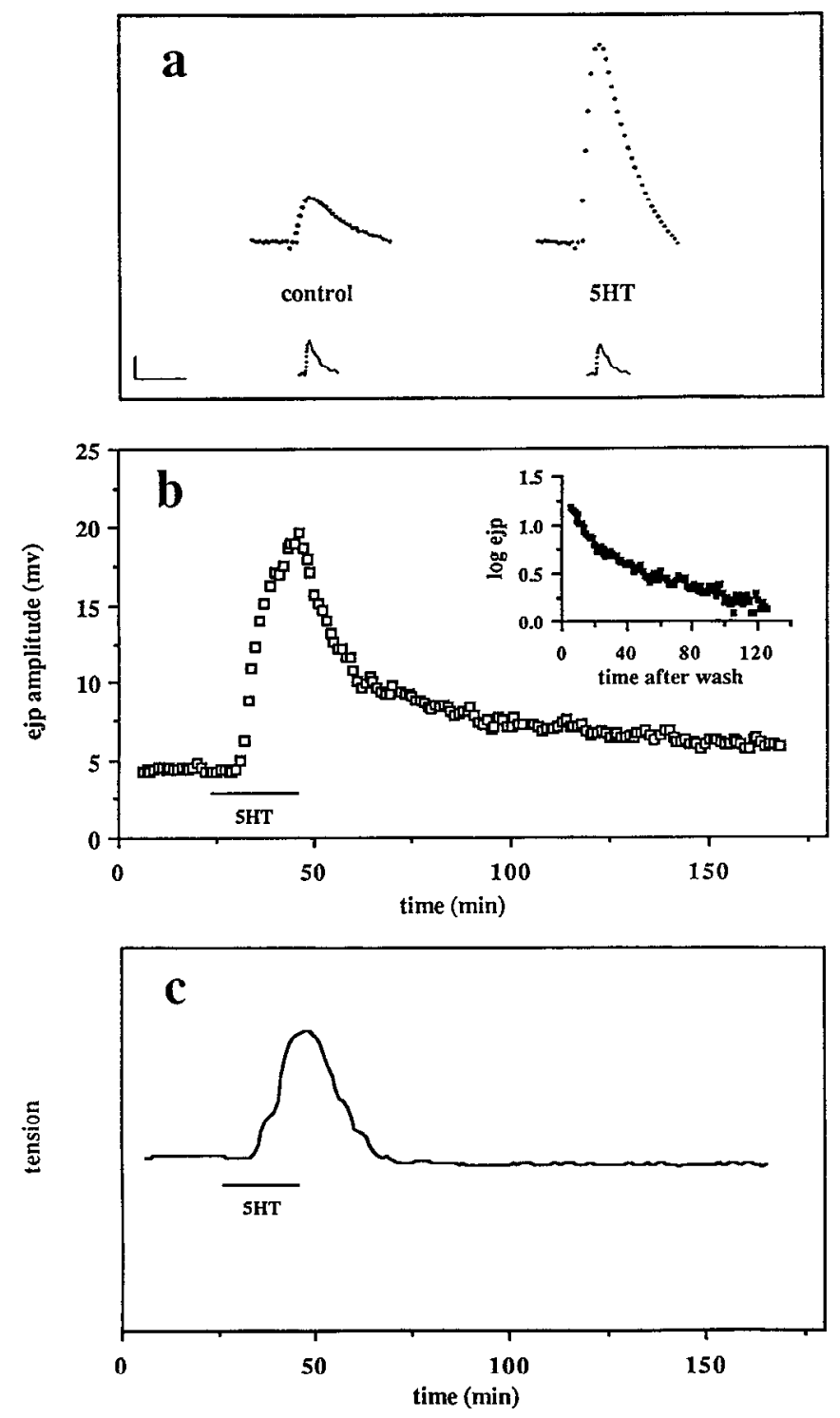

Figure 1. Physiological responses to 5-HT by the lobster neuromuscular preparation. Simultaneous measurements of spontaneous miniature ejp's, evoked ejp's, and muscle tension were obtained in a single experiment. a, Evoked synaptic responses (upper traces) and spontaneous miniature potentials (lower traces) are compared in the presence and absence of $10^{-7} \mathrm{M} 5-\mathrm{HT}$. The ejp records are computer-averages (10 consecutive responses evoked at $0.1 \mathrm{~Hz}$ ) during exposure to control saline or after $20 \mathrm{~min}$ in the presence of the amine. The miniature ejp records are computer averages of 250 spontaneous events collected during a 20 min control period, or during a 30 min interval beginning 4 min after amine treatment. The AC ripple in these traces results from the small size of the spontaneous events relative to the $60 \mathrm{~Hz}$ noise, which leads to increased probability of detecting an event when it occurs on the rising phase of the noise. Calibration bar, $1 \mathrm{mV}$ and $50 \mathrm{msec}$ for upper traces; $0.1 \mathrm{mV}$ and $100 \mathrm{msec}$ for lower traces. $b$. Time course of the change in evoked synaptic potential amplitude during exposure to and washout of 5-HT. Amplitudes were determined from averaged ejp's ( 10 per point, like those shown in $a$ ) and are plotted on the ordinate as a function of time. 5-HT was applied as indicated by the horizontal bar. Inset, Decline in ejp amplitude after washout of $5-\mathrm{HT}$, plotted on a logarithmic scale. The muscle tension data in $c$ are derived from the digitized output of the force transducer, sampled at $0.1 \mathrm{~Hz}$ (just before each evoked ejp). Only relative tension is given, since the force transducer is uncalibrated and the baseline tension varies considerably from experiment to experiment.

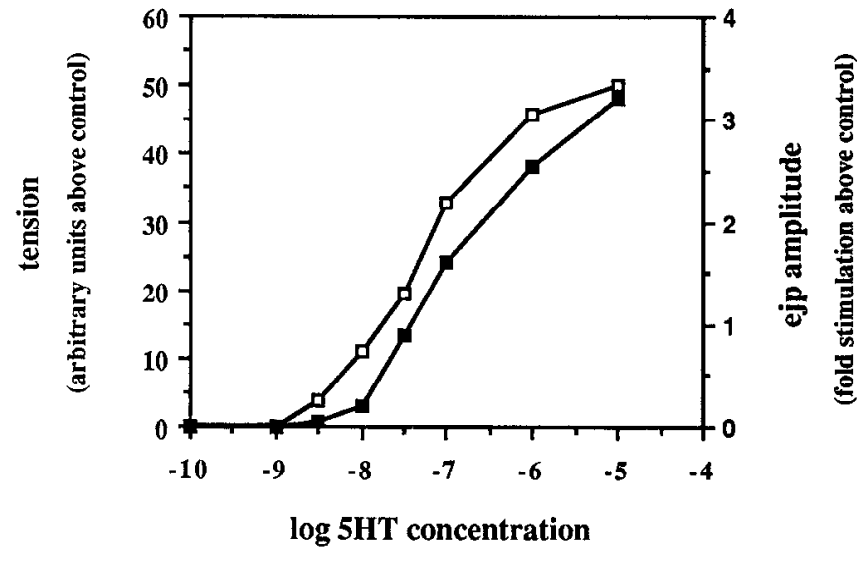

Figure 2. Physiological responses as a function of 5-HT concentration. Muscle tension and ejp amplitude are determined as in Figure 1. All concentrations of 5-HT were tested in a single preparation in order to avoid complication due to variations from preparation to preparation. Tension (-口-) is given in arbitrary units, which indicate relative tension above the baseline level. The ejp amplitude at the peak of the response (-口-) is given as fold stimulation above the control value, with the control determined as the mean amplitude of 100 synaptic potentials evoked prior to 5-HT application.

decaying process accounted for $31.4 \pm 4.2 \%$ of the increase (mean \pm SEM) and decayed with a time constant of $8.1 \pm 1.8$ min (mean \pm SEM). In these experiments the slowly decaying component was observed consistently, while the rapidly decaying component was erratic; its contribution was too small to measure in 2 cases, while in 3 others it accounted for more than $50 \%$ of the total. The rcason for this variability, also noted in earlier studies (Glusman and Kravitz, 1982), is not known.

The time constants for both the rapidly and slowly decaying processes also showed considerable variation in our experiments. One factor that could influence our ability to measure these parameters reproducibly from preparation to preparation is the location of the intracellular microelectrode, since the rate of washout of 5-HT from a superficial recording site might be different from that at a site deep within the muscle. When preparations are incubated with radioactive tracers (either 5-HT or sucrose), the half-time of washout of these labeled compounds from the tissue as a whole is 6-7 min (E. A. Kravitz and B. A. Batelle, unpublished observations). This is comparable to the time course of the rapidly decaying component, and thus variations in the rate of washout from different recording sites might contribute to variations in its time constant. The rate of decay of the slower component, however, is probably too slow to be significantly affected by the rate of washout of the hormone. Variations in this process may reflect seasonal or genetic differences among animals.

\section{Pharmacological effects of agents that perturb cAMP metabolism}

To investigate a possible role of cAMP in the physiological actions of 5-HT, we have examined whether agents that alter cAMP metabolism have parallel effects on the biochemical and physiological properties of the preparation. In particular, we wanted to test the hypothesis that CAMP is the direct trigger for the physiological changes induced by $5-\mathrm{HT}$, perhaps through the well-known protein phosphorylation cascade. If this hypothesis is correct, then manipulation of cAMP levels should have predictable physiological consequences. 

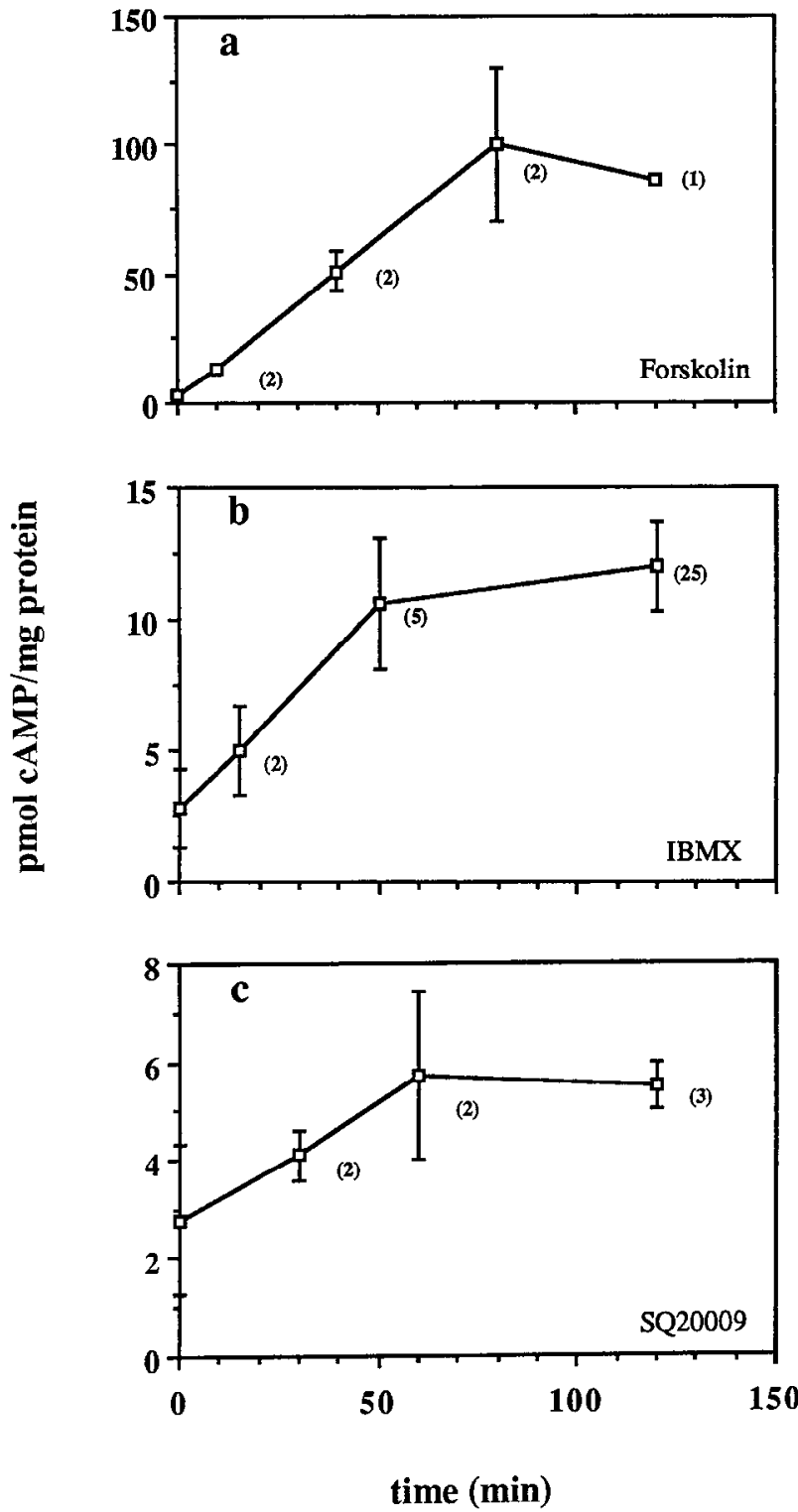

Figure 3. The effects of pharmacological agents on the cAMP content of the neuromuscular preparation. All muscles were preincubated $2 \mathrm{hr}$ in lobster saline, then exposed to $30 \mu \mathrm{M}$ forskolin (a), $0.5 \mathrm{~mm}$ IBMX (b), or $0.2 \mathrm{~mm} \mathrm{SQ20009}(c)$, for the times indicated on the abscissa. The ordinates give the mean cAMP content, measured as described in Materials and Methods, for the number of determinations indicated in parentheses. The control level (at zero time) is the mean of 25 determinations. The error bars give the SEM or, in the case of duplicates, the actual values of the 2 determinations. Because of low solubility, the forskolin stock solution was made up in ethanol; thus all muscles exposed to forskolin were also exposed to $0.2 \%$ ethanol. Control experiments (not shown) indicate that ethanol alone has no effect on cAMP levels, nor does it impair the ability of 5-HT to increase cAMP.

\section{Effects of pharmacological agents on cAMP levels}

Figure 3 shows the cAMP content of the dactyl opener muscle following treatment with an adenylate cyclase activator $(30 \mu \mathrm{M}$ forskolin) or with either of 2 phosphodiesterase inhibitors $(0.5$ mM IBMX or $0.2 \mathrm{~mm} \mathrm{SQ20009).} \mathrm{As} \mathrm{expected,} \mathrm{all} \mathrm{of} \mathrm{these} \mathrm{agents}$ increase cAMP content, which reaches new steady-state levels in 60 to $120 \mathrm{~min}$. We have chosen the concentrations of these drugs to fall within the standard range at which they produce their pharmacological actions, but at a high enough dose that
Table 1. Effect of pharmacological agents on muscle tension and responses to $5-\mathrm{HT}$

\begin{tabular}{|c|c|c|}
\hline Agent & $\begin{array}{l}\text { A } \\
\text { Increase in tension } \\
\text { induced by agent } \\
\text { (as \% of control } \\
5 \text {-HT response) }\end{array}$ & $\begin{array}{l}\text { B } \\
\text { Response to 5-HT in } \\
\text { presence of agent } \\
\text { (as \% of control } 5-\mathrm{HT} \\
\text { response) }\end{array}$ \\
\hline 年 & & $53.5=$ \\
\hline SQ20009 & 31.2 & $68.0 \pm 8.6 \quad(n=4)$ \\
\hline Forskolin, $3 \times 10^{-5} \mathrm{M}$ & $7.0 \pm 2.1(n=6)$ & $96.1 \pm 3.1 \quad(n=2)$ \\
\hline omo cAMP, $10^{-2} \mathrm{M}$ & $125+56(n-1$ & $57.5 \pm 12.8(n=3)$ \\
\hline
\end{tabular}

Data were collected and analyzed as described in Materials and Methods. Each entry comes from an experiment like those illustrated in Figure 4 (with the total number of experiments given in parentheses). Values in the middle column represent the tension response to the indicated pharmacological agent as a percent of the initial response to 5-HT. Values in the last column represent the tension response to a second 5-HT treatment (in the continued presence of the agent) as a percent of the initial response. The mean and SE (or range, in the case of duplicates) are given. If no pharmacological agent was added, the responses to 2 consecutive exposures to 5-HT are nearly identical (data not shown).

they have greater effects on intracellular cAMP levels than does 5-HT. The increases range from 1.7-fold for SQ20009 to more than 30 -fold for forskolin. For comparison, incubation with $10^{-7}$ M 5-HT (in the absence of a phosphodiesterase inhibitor) causes about a 1.3-fold increase in cAMP levels (see Fig. 9a).

Another compound often used to mimic the effects of internal cAMP is 8-bromo cAMP. This analog crosses the cytoplasmic membrane and, because it is resistant to phosphodiesterase, gradually accumulates inside cells. We have not directly measured internal levels of 8-bromo cAMP after adding it to the extracellular medium, but we know that it accumulates intracellularly to high enough concentrations to activate a protein kinase that phosphorylates a cytoplasmic protein in these preparations (Goy et al., 1984). A $60 \mathrm{~min}$ incubation with $1 \mathrm{~mm}$ 8-bromo cAMP produces phosphorylation approximately equivalent to that produced by $10^{-6} \mathrm{M} 5-\mathrm{HT}$. For the experiments in this paper we have used a 10-fold higher concentration $(10 \mathrm{mM})$ in order to ensure that the analog reaches significant levels in the cytoplasm.

\section{Effects of pharmacological agents on muscle tension}

The agents described in the preceding section were tested for the ability to mimic the postsynaptic actions of 5-HT. We measured muscle tension before, during, and after superfusion with each substance at the concentration indicated above. Under these conditions, as we have demonstrated, the drugs were all more effective than 5-HT at influencing cAMP metabolism (or protein phosphorylation). None, however, was able to produce tension comparable to that of 5-HT, although small increases in tension were observed in some experiments with 8-bromo cAMP, forskolin, and SQ20009 (Fig. 4 and Table 1, column A). It seemed possible, especially in light of this small increase in tension, that these agents might be activating the contractile apparatus of the muscle just as vigorously as $5-\mathrm{HT}$, but that some additional effect of the drugs was simultaneously inhibiting the contraction. To control for this, we added 5-HT at the end of each experiment (in the continuous presence of the pharmacological agent being tested) and showed that the preparation could still respond to the hormone (Fig. 4 and Table 1, column B), although in some cases the size of the response to the second application of 5-HT was slightly reduced. 

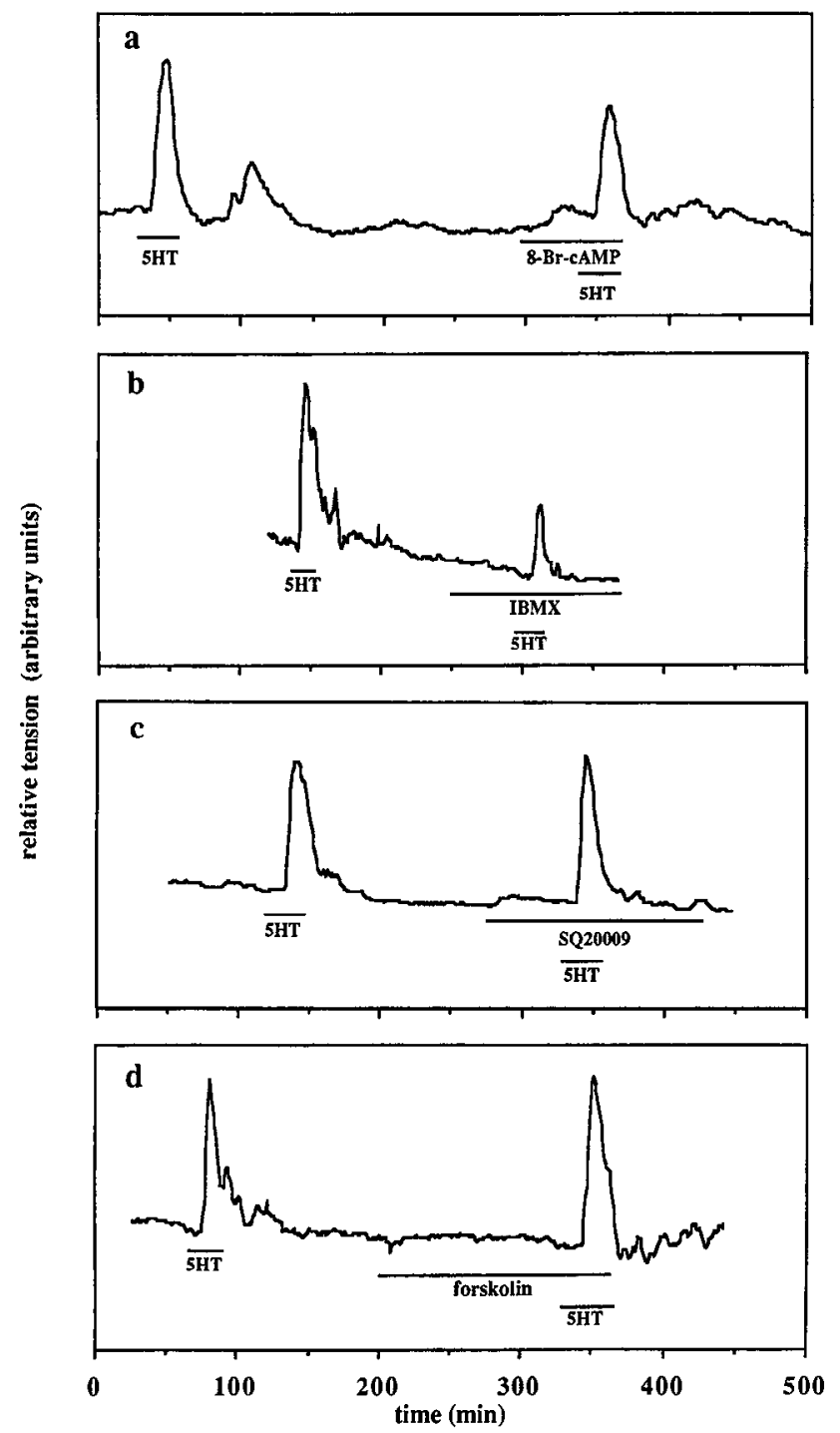

Figure 4. Effects on muscle tension of pharmacological agents that perturb cAMP metabolism. 5-HT was used at $10^{-7} \mathrm{M}$, IBMX at $0.5 \mathrm{~mm}$, SQ20009 at $0.2 \mathrm{~mm}$, forskolin at $30 \mu \mathrm{M}$, and 8-bromo cAMP at $10 \mathrm{~mm}$. All agents were added to the superfusing saline during the intervals indicated by the horizontal bars. For the experiment with forskolin, $0.2 \%$ ethanol was present throughout. At this concentration, ethanol has no effect on muscle tension. Each result presented here is representative of 3 or more experiments (as indicated in Table 1).

\section{Effects of pharmacological agents on ejp amplitude}

In contrast to their inability to enhance muscle tension significantly, all of the drugs that elevate cAMP were able to increase the amplitude of the ejp's (Fig. 5 and Table 2). The observation that the amplitude of spontaneous miniature ejp's does not increase in parallel with that of the evoked ejp's (Table 2) indicates that neither the size of the quantum nor the sensitivity of the postsynaptic membrane to the transmitter is being affected and suggests that the drugs cause an increase in evoked release of transmitter. This supports the idea that these drugs are acting presynaptically in the same way that 5-HT does and indicates that cAMP can act as an intracellular messenger to enhance transmitter release from crustacean motor nerve terminals.

However, although all of the drugs tested consistently increased the amplitude of the evoked synaptic potential, none of
Table 2. Effect of pharmacological agenis on the amplitude of evoked ejp's and spontaneously occurring miniature ejp's

\begin{tabular}{llr} 
& $\begin{array}{l}\text { Evoked ejp } \\
\text { amplitude } \\
\text { (\% control) }\end{array}$ & \multicolumn{1}{l}{$\begin{array}{l}\text { Miniature ejp } \\
\text { amplitude } \\
\text { (\% control) }\end{array}$} \\
\hline Agent & $440 \pm 30(n=17)$ & $97.8 \pm 0.9(n=5)$ \\
IBMT, $10^{-7} \mathrm{M}$ & $139 \pm 4(n=4)$ & $100.4 \pm 0.4(n=2)$ \\
SQ20009, $2 \times 10^{-4} \mathrm{M}$ & $221 \pm 36(n=4)$ & $100.7 \pm 0.7(n=2)$ \\
Forskolin, 3 $\times 10^{-5} \mathrm{M}$ & $155 \pm 15(n=4)$ & $99.5 \pm 1.8(n=3)$ \\
8-Bromo cAMP, 10-2 $\mathrm{M}$ & $229 \pm 12(n=2)$ & $99.8(n=1)$
\end{tabular}

Data were collected and averaged by computer, as described in Materials and Methods. Each entry in this table comes from an experiment like those illustrated in Figure 5 (with the total number of experiments given in parentheses). For evoked synaptic potentials, the amplitude of 20 averaged records at the peak of the response to each pharmacological agent is given as a percent of the amplitude of 20 averaged control records. For miniature ejp's, the average amplitude of 200-1000 events collected over 10-30 min of exposure to each pharmacological agent (during the period when evoked synaptic potentials were showing their maximum increase) is given as a percent of an equivalent number of events collected during control periods. The mean and SE (or range, in the case of duplicates) are given. For forskolin, data were obtained in the presence of $0.2 \%$ ethanol and are compared with control values obtained under identical conditions.

them had as large an effect as 5-HT (Fig. 5 and Table 2). This discrepancy is particularly remarkable for forskolin, which causes much larger increases in cAMP content than 5-HT, yet produces, on average, an increase in ejp amplitude less than onesixth that of the hormone (Table 2). A possible explanation for these results is that cAMP might mediate only part of the presynaptic response and that 5 -HT might have an additional, cAMP-independent effect on transmitter release. Since the presynaptic action of 5-HT has 2 distinguishable components, we attempted to test the cAMP dependence of each.

\section{Comparison of physiological and biochemical time courses}

As mentioned above, and shown in Figure 1, the 2 presynaptic components are defined in terms of the rate at which they decay following washout of 5-HT. The more rapidly decaying component has returned to control levels within 10-20 min after washout, whereas the slowly decaying component requires $2-3$ $\mathrm{hr}$ for complete reversal. The time course of the 5-HT-induced cAMP changes is too slow to correlate well with the former but does approximate the latter. It is also too slow to correlate well with the time course of the postsynaptic response. As shown in Figure 6 (open symbols) at 15 min after washout of 5-HT, cAMP levels have declined only $10 \%$ from the peak response, and at 90 min they are still $30 \%$ above the control level. Of the 3 processes under consideration, only the slowly decaying component of the presynaptic response is still active $90 \mathrm{~min}$ after washout.

As a more direct test of the idea that cAMP mediates the slowly decaying presynaptic response to $5-\mathrm{HT}$, but not the rapidly decaying presynaptic or the postsynaptic responses, we compared the effects of IBMX on cAMP levels and physiology following washout of the aminc. Since IBMX inhibits the enzyme that metabolizes cAMP, it is expected to block or retard the breakdown of the cyclic nucleotide after 5-HT has been removed, and hence to block or retard the decay of any physiological process that depends on cAMP. Figure 6 confirms that IBMX has the predicted biochemical effect; the inhibitor dramatically prolongs the time course of the 5-HT-induced increase in cAMP levels (filled symbols).

The physiological effects of IBMX are consistent with the idea 

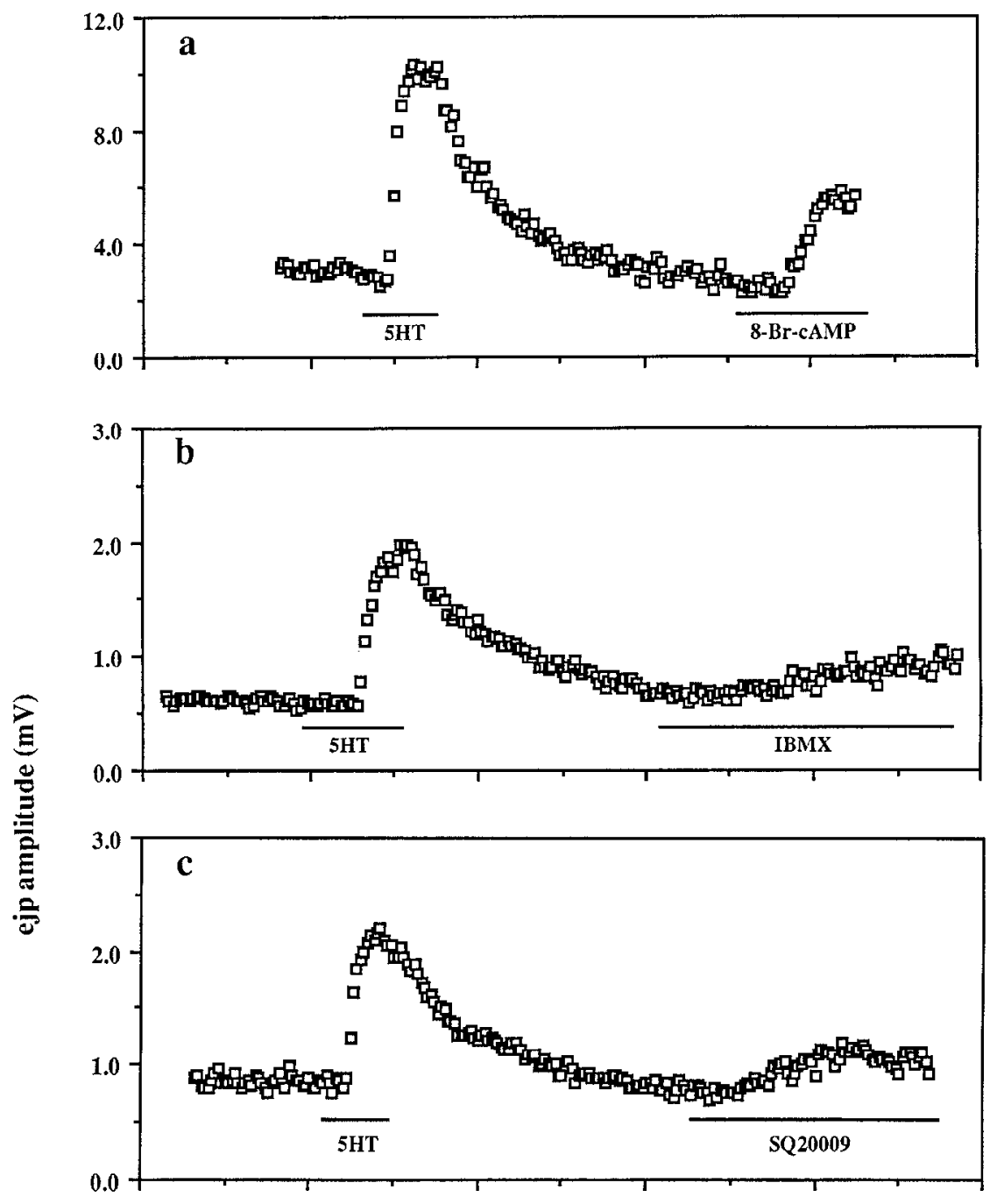

Figure 5. The effects on ejp amplitude of pharmacological agents that perturb cAMP metabolism. Each data point is the mean amplitude of 10 consecutive ejp's, as in Figure 1. 5-HT was used at $10^{-7} \mathrm{M}, \mathrm{IBMX}$ at $0.5 \mathrm{mM}, \mathrm{SQ} 20009$ at $0.2 \mathrm{mM}$, forskolin at $30 \mu \mathrm{M}$, and 8-bromo cAMP at $10 \mathrm{~mm}$. All agents were added to the superfusing saline during the intervals indicated by the horizontal bars. For the experiment with forskolin, $0.2 \%$ ethanol was present throughout. At this concentration, ethanol has no effect on ejp amplitude. Each result presented here is representative of 2 or more experiments (as indicated in Table 2).

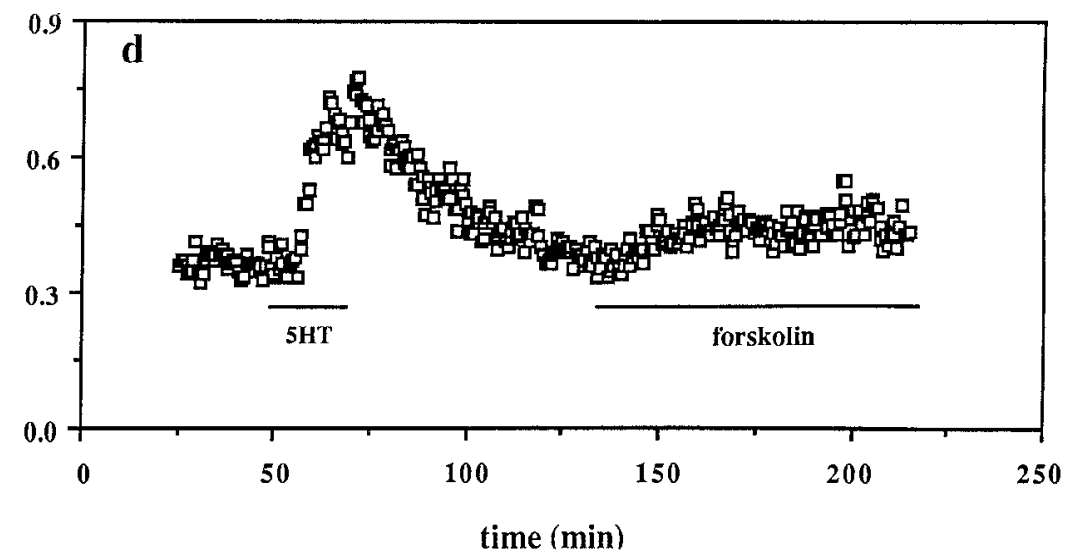

that cAMP is primarily (or exclusively) associated with the slower component of the presynaptic response. The evidence supporting this is as follows. (1) In 10 out of 10 experiments in which IBMX was applied during the washout of 5-HT, the phosphodiesterase inhibitor had no noticeable effect on the time course of the postsynaptic change in muscle tone (see, for example, Figs. $4 b$ and $8 b$ ). (2) In 8 of these experiments we also monitored synaptic potential amplitude. Here, in contrast to the lack of postsynaptic effect, we consistently observed an IBMX-dependent decrease in the rate of washout of the presynaptic response. (3) This effect of IBMX appears to be pri- marily on the slower of the 2 presynaptic components. The most convincing demonstration of this is shown in Figure $7 a$. In this particular experiment, the decay of the slower component was completely blocked by IBMX, whereas the rapidly reversing component was unaffected. The remaining 7 experiments gave similar results, although the block of the slow component's decay was not always as complete as that shown in Figure $7 a$. In order to determine the average effect of IBMX on the 2 presynaptic components, we added all 8 experiments together, as described in the legend to Figure 7. The time constant of the slow component of this composite response (shown in Fig. $7 b$ ) 


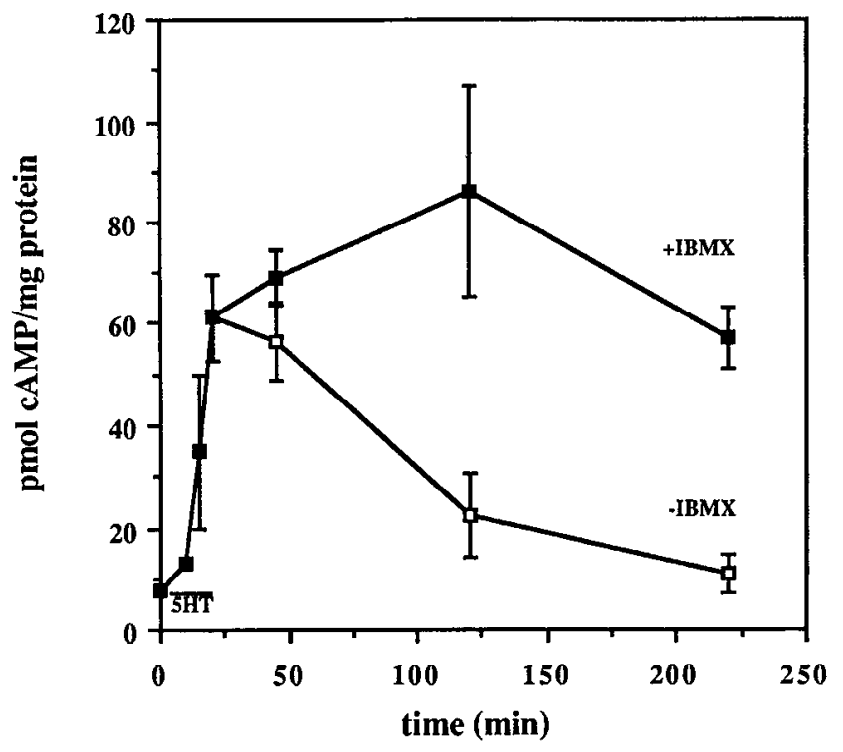

Figure 6. IBMX inhibits the breakdown of cAMP after 5-HT is removed. Isolated neuromuscular preparations were preincubated for 2 $\mathrm{hr}$ in $0.5 \mathrm{~mm}$ IBMX, and then exposed to $10^{-6} \mathrm{M} 5-\mathrm{HT}$ (as indicated by the horizontal bar). The cAMP level was determined in individual preparations at the times indicated (-口-). Then (after 15 min exposure to the amine) either 5-HT (- - ) or both 5-HT and IBMX (- --$)$ were removed by extensive washing, and the cAMP level was determined in individual preparations at intervals over the next $2 \mathrm{hr}$. Each point is the mean of 2 to 6 determinations, and the error bars indicate the SEM, or the range in the case of duplicate measurements.

increases by more than 10 -fold, from $30.8 \mathrm{~min}$ in the absence to $332.4 \mathrm{~min}$ in the presence of IBMX. This is in good agreement with the effects of IBMX on the time course of cAMP metabolism shown in Figure 6.

After averaging the data, the time constant determined for the faster component also increases slightly in the presence of IBMX, from 2.7 to $8.2 \mathrm{~min}$. It is possible that this reflects an involvement of CAMP in the more rapid presynaptic process as well. However, compared with the effect of IBMX on 5-HTstimulated cAMP levels (Fig. 6), the effect on the time constant of the rapid component is relatively insignificant."

In onc cxperiment, we subjected a preparation to 2 sequential exposures to 5-HT during a single prolonged treatment with IBMX (Fig. 8). Both responses in the presence of IBMX were similar to the control response in the absence of IBMX, except that the decay of the slower presynaptic component was consistently retarded. The fact that the more rapid presynaptic component and the postsynaptic response decayed normally and could be evoked repeatedly shows that their decay is a true reversal, and not an artifact of fatigue or damage to the muscle or nerve. The failure of the slow component to decay, and the fact that the third exposure to 5-HT initiates primarily the rapidly decaying presynaptic component, is consistent with the idea that in this experiment the phosphodiesterase inhibitor has kept the levels of cAMP high enough to activate a significant fraction of the slow component and has left little room for further activation of this component by subsequent 5-HT treatments.

\section{Agents that potentiate cAMP accumulation}

In other systems, IBMX and forskolin generally amplify the effects of hormones on intracellular levels of cAMP, an effect that in turn potentiates those physiological processes that depend on CAMP. Thus, potentiation by these drugs is often cited as evidence for the involvement of cAMP in a particular physiological response (Greengard, 1976; Seamon and Daley, 1983). We have used the properties of these drugs as a final test of the physiological role played by CAMP in the lobster preparation.

Figure 9 demonstrates that forskolin and IBMX dramatically increase the ability of 5-HT to stimulate the level of cAMP in lobster nerve-muscle preparations. Under normal conditions

${ }^{1}$ Therefore, we feel that it more likely results from unrelated side effects of IBMX, such as its well-known ability to release $\mathrm{Ca}^{2+}$ from intracellular storage sites. This interpretation would be consistent with the recent observation that intra-axonal injection of inositol tris-phosphate (which also releases $\mathrm{Ca}^{2+}$ from intracellular storage sites) induces a rapid, transient facilitation of transmitter release from crayfish motor terminals (Dixon and Atwood, 1987.
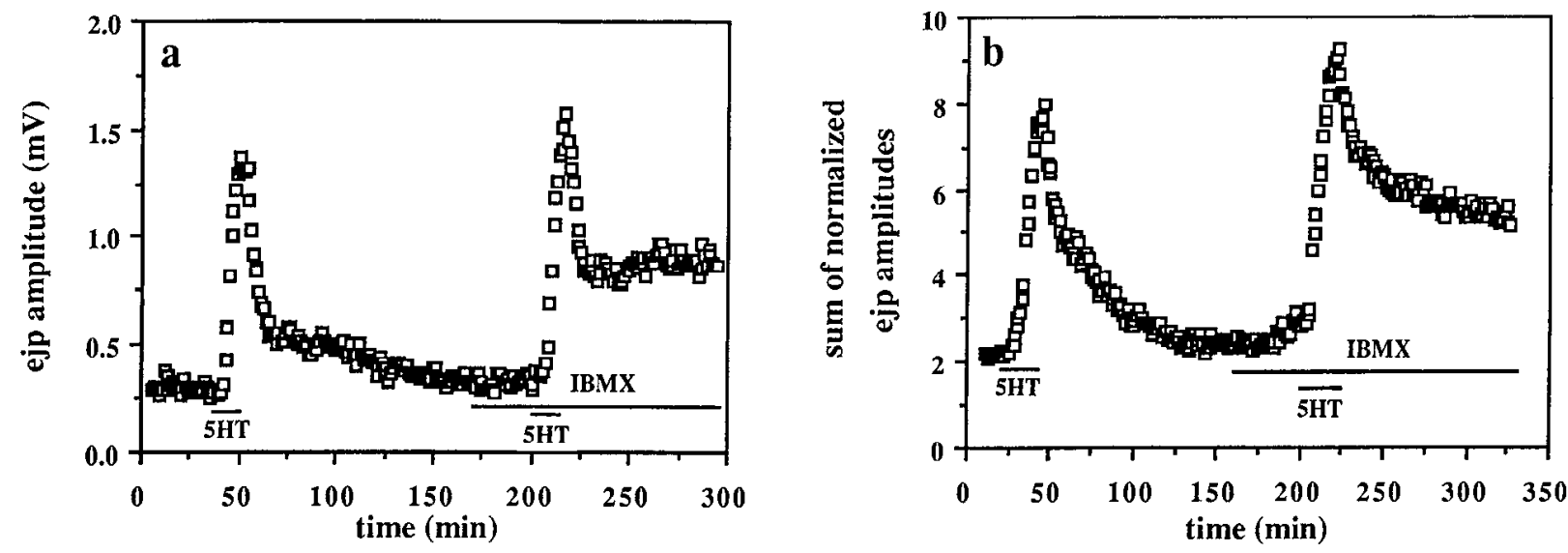

Figure 7. IBMX selectively retards the decay of one component of presynaptic facilitation after 5-HT is removed. a, Each point gives the mean amplitude of 10 consecutive ejp's, at a stimulus rate of $0.1 \mathrm{~Hz}$, obtained in a single experiment. IBMX $(0.5 \mathrm{mM})$ and $5-\mathrm{HT}\left(10^{-7} \mathrm{M}\right)$ were added to the superfusing saline during the intervals indicated by the horizontal bars. $b$, Pooled results from 8 separate experiments. The schedule of exposure to 5 -HT $\left(10^{-7} \mathrm{M}\right)$ and IBMX $(0.5 \mathrm{mM})$ was exactly the same in all 8 experiments, and is indicated by the horizontal bars. Within each experiment, each data point was obtained as the mean amplitude of 10 consecutive ejp's evoked at $0.1 \mathrm{~Hz}$. The experiments were then individually normalized by dividing each data point in the sequence by the value of the highest point obtained during the initial response to 5-HT. This scaling factor gave each experiment equal weight, by defining the peak value of the control 5-HT response as 1 . The experiments were then pooled by simple addition, so that each point in the composite time course represents the sum of the weighted contributions of all 8 experiments. The composite data were then mathematically fit as the sum of 2 exponentials (see Materials and Methods) to give the time constants reported in Results. 

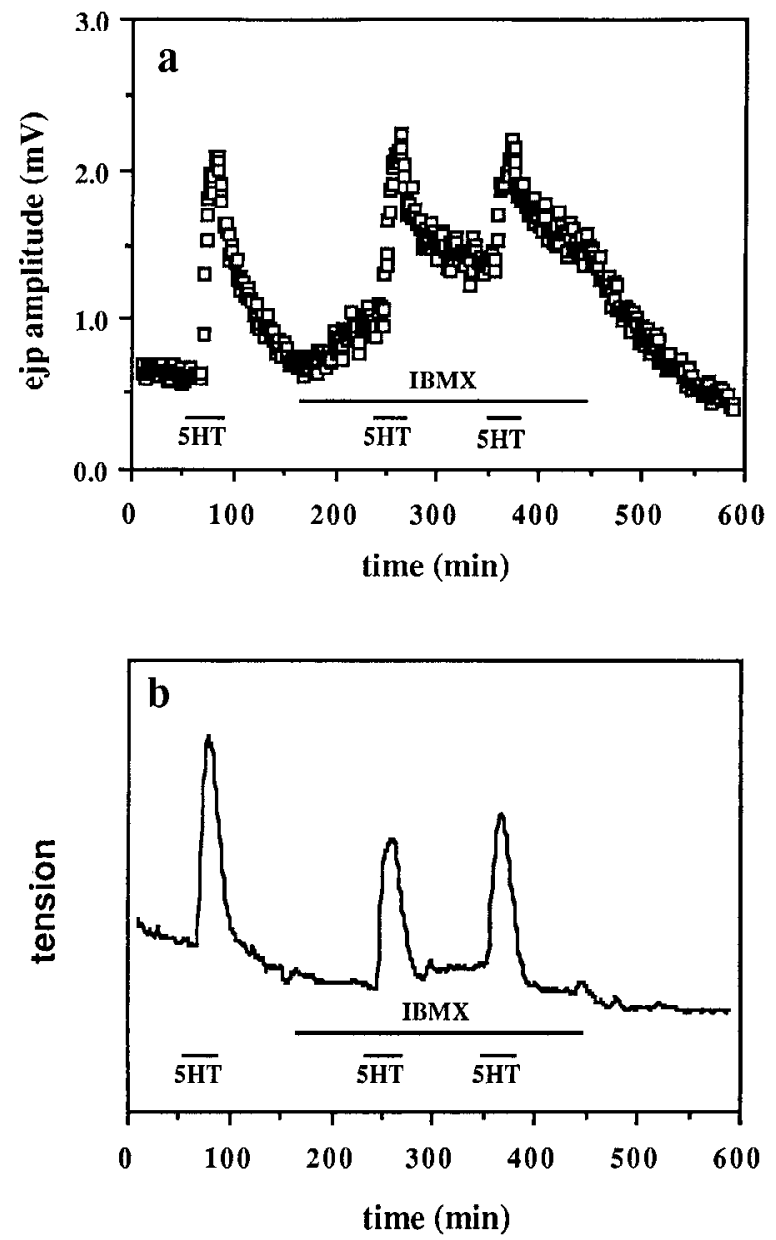

Figure 8. Multiple exposures to 5-HT during IBMX treatment. Each point in a gives the mean amplitude of 10 consecutive ejp's, at a stimulus rate of $0.1 \mathrm{~Hz}$. Muscle tension from the same experiment is plotted in $b$. IBMX $(0.5 \mathrm{~mm})$ and $5-\mathrm{HT}\left(10^{-7} \mathrm{M}\right)$ were added to the superfusing saline during the intervals indicated by the horizontal bars.

(no added drugs), $10^{-7} \mathrm{M} 5$-HT increases the level of cAMP in these tissues by about $1 \mathrm{pmol} / \mathrm{mg}$ protein. In contrast, in the

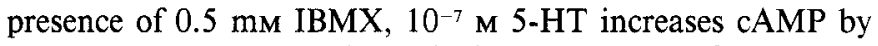
about $10 \mathrm{pmol} / \mathrm{mg}$ protein, while in the presence of $30 \mu \mathrm{M}$ forskolin the increase is about $100 \mathrm{pmol} / \mathrm{mg}$ protein.

We tested the ability of these drugs to potentiate either the pre- or the postsynaptic responses of nerve-muscle preparations to a test dose of 5-HT. The effect of $10^{-7}$ M 5-HT on ejp amplitude in the absence and presence of $30 \mu \mathrm{M}$ forskolin is shown in Figure $10 a$. Both the rapidly and slowly decaying components of the response are visible in this experiment, and it is apparent that forskolin potentiates the slowly decaying component, with no potentiation (in fact, a slight inhibition) of the rapidly decaying component. A similar result is obtained with IBMX (Fig. $10 b$ ). In contrast, it is clear from the results presented in Figure 4 and Table 1 that neither forskolin nor IBMX potentiates the postsynaptic response to $10^{-7} \mathrm{M} 5-\mathrm{HT}$. This concentration of 5 -HT is sufficiently below saturation (Fig. 2) such that potentiation should have been observed, had it occurred. Thus, in the presence of potentiating drugs, once again only 1 of the 3 physiological actions under consideration (the slowly decaying component of the presynaptic response) shows a correlation with cAMP levels.
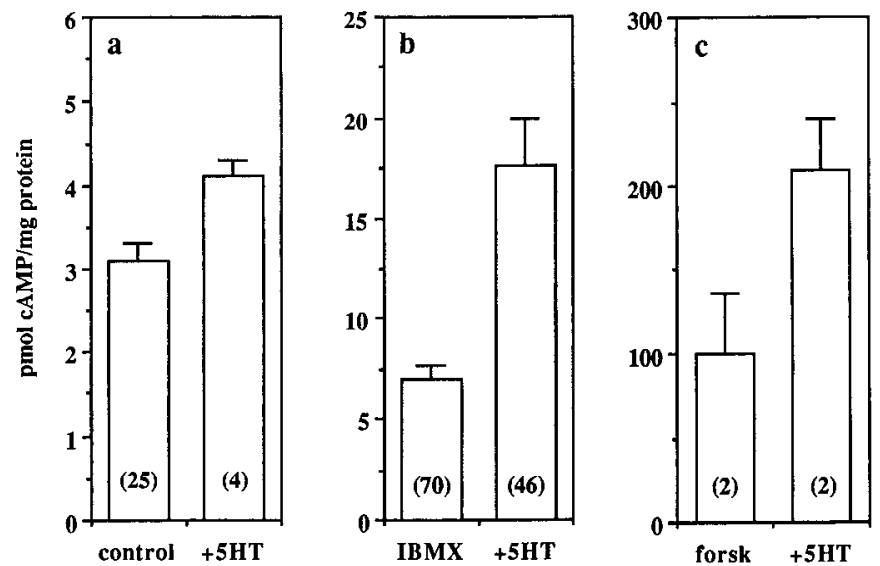

Figure 9. Forskolin and IBMX potentiate the effect of 5-HT on cAMP levels. Muscles were exposed to a control solution or to $10^{-7}$ м 5-HT for $15 \mathrm{~min}$ after a $2 \mathrm{hr}$ preincubation in normal saline $(a)$, a $2 \mathrm{hr}$ preincubation in saline plus $0.5 \mathrm{mM} \operatorname{IBMX}(b)$, or an $80 \mathrm{~min}$ preincubation in saline plus $30 \mu \mathrm{M}$ forskolin (c). Each bar is the mean of the number of determinations given in parentheses. The error bars indicate the SEM, or the range in the case of duplicate measurements. Ethanol $(0.2 \%)$ was present in the saline of all muscles exposed to forskolin. Control experiments (not shown) demonstrate that ethanol does not affect cAMP by itself, nor does it potentiate the effect of 5-HT.

\section{Discussion}

5-HT exerts a complex set of modulating influences in lobster neuromuscular preparations. Excitatory and inhibitory nerve terminals and muscle fibers are all involved, and many of the hormone-induced changes are prolonged. In this communication we have investigated possible links between the 5-HTinduced changes in junctional physiology and the parallel 5-HTinduced increases in the levels of cAMP.

The physiological focus has been on the enhancement of transmitter release from excitatory nerve terminals and on the increase in tone of the muscle fibers. cAMP-linked modulation of similar physiological processes has been seen in many other animal species. cAMP has been associated with enhanced release of secretory products in a variety of tissues, including insect and vertebrate salivary glands (reviewed by Berridge, 1982), mammalian anterior pituitary (reviewed by Labrie et al., 1982), adrenal chromaffin cells (reviewed by Weiner, 1979), vertebrate sympathetic nerve terminals (reviewed by Weiner, 1979), vertebrate motor nerve terminals (reviewed by Bowman, 1981; Dunwiddie and Hoffer, 1982), and molluscan sensory nerve terminals (reviewed by Kandel and Schwartz, 1982). In addition, cAMP has been implicated in modulation of contractility in many types of muscle. In vertebrates, catecholamines, acting through beta-adrenergic receptors, produce cAMP increases that are suggested to be involved in the positive inotropic response of cardiac muscle (Tsien, 1977; Lindner et al., 1978; Osterrieder et al., 1982; Reuter, 1983; Kameyama et al., 1985), the rclaxation of many types of smooth muscle (Conti and Adelstein, 1980; Dubey et al., 1981; Kerrick and Hoar, 1981), and changes in the contractility of both fast and slow skeletal muscle (reviewed by Rodger and Bowman, 1983). In invertebrates, cAMP has also been implicated in regulation of muscle tone and contractility in several different species (Weiss et al., 1979; Kohler and Lindl, 1980; Fujiwara and Kobayashi, 1983; Evans, 1984).

The results presented in this paper suggest that of the 3 phys- 

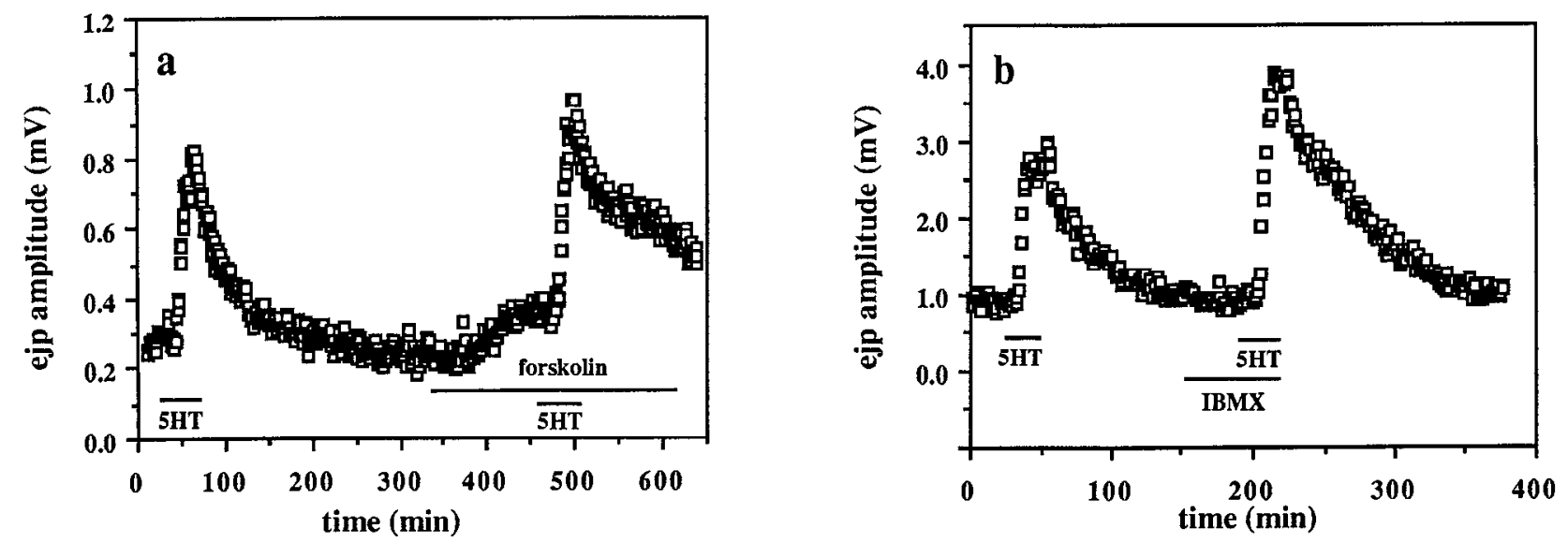

Figure 10. Potentiation by forskolin and IBMX of 5-HT's effect on ejp amplitude. The data in $a$ and $b$ are each representative of several similar experiments. Every data point gives the mean amplitude of 10 consecutive ejp's, at a stimulus rate of $0.1 \mathrm{~Hz}$. $a$, Forskolin $(30 \mu \mathrm{M})$ and $5-\mathrm{HT}\left(10^{-7}\right.$ M) were added to the superfusing saline during the intervals indicated by the horizontal bars. Ethanol $(0.2 \%)$ was present throughout the experiment. $b$, IBMX $(0.5 \mathrm{mM})$ and 5-HT $\left(10^{-7} \mathrm{M}\right)$ were added as indicated.

iological actions of 5-HT that we have analyzed (2 distinguishable presynaptic effects, and a third postsynaptic effect), only one of the presynaptic responses appears to be cAMP dependent. The other physiological actions apparently are not directly mediated by this cyclic nucleotide. The evidence supporting this may be summarized as follows. (1) Agents that mimic the action of 5-HT on cAMP levels fail to mimic the 5-HT-induced contraction (Fig. 4). (2) In contrast, every agent that increases cAMP levels does enhance transmitter release (Fig. 5; see Enyeart, 1981, for relatcd studics at the crayfish neuromuscular junction). Since these agents all act by very different mechanisms, it is unlikely that this facilitation results from nonspecific pharmacological side effects. (3) However, none of these agents has as potent a facilitating action as 5-HT, even though some of them increase cAMP much more powerfully than the amine. When the 2 components of the presynaptic response to 5-HT are analyzed separately, only the slowly decaying component appears likely to depend on cAMP metabolism (see Dixon and Atwood, 1987, for a preliminary report of related studies at the crayfish neuromuscular junction); agents that potentiate the cAMP response potentiate this component (Fig. 10), and agents that block the breakdown of cAMP block the decay of this component when 5 -HT is washed out of the preparation (Fig. 7). These agents do not increase the magnitude or greatly affect the time course of the faster presynaptic component or of the postsynaptic response (Figs. 4, 7, 8, 10). (4) Finally, the time course of the change in cAMP levels following exposure to 5-HT parallels that of the slowly decaying presynaptic physiology, but not that of the postsynaptic response or of the rapidly decaying presynaptic component (compare Figs. 6 and 1).

Although these results taken together are consistent with the idea that changes in cAMP metabolism mediate one, and possibly only one, of the multiple effects of 5-HT in this preparation, several reservations should be mentioned. First, we have taken as the simplest hypothesis the idea that cAMP directly triggers one component of presynaptic facilitation, a hypothesis that is consistent with all of our data. However, more complex interpretations are possible. For example, rather than triggering the response itself, cAMP might in some way inhibit the breakdown of a different second messenger that is the real signal that triggers the response. Experiments to rule out hypotheses of this sort must await the development of an in vitro model, where all the biochemical components of the system can be controlled. Second, the responses that we believe are not directly triggered by cAMP might nevertheless involve cAMP in some indirect way. This is important with regard to both muscle tension (since 8-bromo cAMP, forskolin, and SQ20009 have small effects on this parameter) and to the fast component of presynaptic facilitation (since IBMX causes a slight retardation of the washout of this component after removal of 5-HT). Third, although we have tried to document the ways in which cAMP metabolism correlates (or fails to correlate) with pre- and postsynaptic physiology, our cAMP measurements are made on a preparation that contains both nerve terminals and muscle fibers, and the relative changes in cyclic nucleotide levels in each tissue cannot be independently determined. Because the muscle fibers constitute the vast majority of the tissue mass, our measurements most likely reflect changes in this tissue compartment. Thus, the observation that forskolin dramatically increases CAMP content without significantly increasing tension provides strong evidence that the postsynaptic response is not directly mediated by cAMP. However, we also believe that the pharmacological agents do alter nerve terminal cAMP levels, since they change nerve terminal physiology. Moreover, the physiological effects of these agents are consistent with the idea that the level of nerve terminal cAMP is proportional to the level of total tissue cAMP.

The modulation of transmitter release from excitatory motor nerve terminals in the lobster is analogous to the modulation of transmitter release from sensory nerve terminals that has been studied in the abdominal ganglion of the mollusc Aplysia californica. In both systems 5-HT causes an increase in transmitter output, and in both systems cAMP is probably involved in at least part of the enhancement. The molluscan preparation provides one of the best studied and best understood examples of synaptic modulation by 5 -HT. In this preparation, Kandel and colleagues have shown that 5-HT causes an increase in cAMP in individually dissected sensory neurons (Bernier et al., 1982). They have also shown that cAMP inhibits an outward $\mathrm{K}^{+}$current involved in repolarizing the cell body membrane during the action potential (Klein and Kandel, 1980; Siegelbaum et al., 1982), thus broadening the spike. As a result, voltage-dependent $\mathrm{Ca}^{2+}$ channels in the cell body (and, by extrapolation, in the 
nerve terminals) remain open longer during regenerative clcctrical activity, more $\mathrm{Ca}^{2+}$ enters, and by this mechanism release of transmitter is thought to be enhanced (Klein and Kandel, 1980). This effect of 5-HT can be mimicked by phosphodiesterase inhibitors (Klein and Kandel, 1978) and by intracellular injection of cAMP (Brunelli et al., 1976) or the catalytic subunit of the cAMP-dependent kinase (Castellucci et al., 1980). Furthermore, the actions of 5-HT can be antagonized by intracellular injection of an inhibitor of the kinase (Castellucci et al., 1982).

Although the crustacean neuromuscular preparation has not been analyzed in the same detail, it is nevertheless evident that it shows several qualitative differences from the molluscan preparation. Intracellular recordings from the axon of the excitatory nerve innervating the crayfish dactyl opener muscle reveal that 5-HT depolarizes the axonal membrane and produces a small increase in membrane conductance, probably to $\mathrm{Na}^{+}$ions, but does not produce a decrease in $\mathrm{K}^{+}$conductance similar to that observed in Aplysia sensory neurons (Dixon and Atwood, 1985). Also, in addition to possible changes in surface membrane channels, the crustacean studies suggest that intracellular mechanisms may play a role in the amine-induced modulation of transmitter release (Glusman and Kravitz, 1982; Dixon and Atwood, 1985, 1987). Furthermore, in contrast to the single mechanism reported for Aplysia, 5-HT appears to enhance transmitter release by 2 distinguishable mechanisms in crustacean motor nerve terminals, only one of which involves cAMP. Finally, 5-HT has a third (postsynaptic) action in Crustacea that is also cAMP independent and that appears to involve changes in membrane calcium channels. This latter observation offers the prospect of investigating a potentially novel biochemical mechanism for modulation by $5-\mathrm{HT}$. The favorable properties of this neuromuscular preparation for studies of muscle biochemistry (a relatively homogeneous tissue composed primarily of muscle fibers, and available in large quantities) should greatly facilitate such studies.

\section{References}

Aghajanian, G. K. (1981) The modulatory role of serotonin at multiple receptors in brain. In Serotonin, Neurotransmission and Behavior, B. L. Jacobs and A. Gelperin, eds., pp. 156-185, MIT Press, Cambridge, MA.

Battelle, B. A., and E. A. Kravitz (1978) Targets of octopamine action in the lobster: Cyclic nucleotide changes and physiological effects in haemolymph, heart, and exoskeletal muscle. J. Pharmacol. Exp. Ther. 205: 438-448.

Beltz, B. S., and E. A. Kravitz (1983) Mapping of serotonin-like immunoreactivity in the lobster nervous system. J. Neurosci. 3: 585602.

Bernier, L., V. F. Castellucci, E. R. Kandel, and J. H. Schwarte (1982) Facilitatory transmitter causes a selective and prolonged increase in adenosine $3^{\prime}, 5^{\prime}$-monophosphate in sensory neurons mediating the gill and siphon withdrawal reflex in Aplysia. J. Neurosci. 2: 1682-1691.

Berridge, M. J. (1982) Regulation of cell secretion: The integrated action of cyclic AMP and calcium. In Handbook of Experimental Pharmacology, Vol. 58, Pt. 2, J. W. Kebabian and J. A. Nathanson, eds. pp. 227-270, Springer-Verlag, Berlin.

Bowman, W. C. (1981) Fffects of adrenergic activators and inhibitors on the skeletal muscles. In Handbook of Experimental Pharmacology, Vol. 54, Pt. 2, J. W. Kebabian and J. A. Nathanson, eds., pp. 47128 , Springer-Verlag, Berlin.

Brunelli, M., V. F. Castellucci, and E. R. Kandel (1976) Synaptic facilitation and behavioral sensitization in Aplysia: Possible role of serotonin and cyclic AMP. Science 194: 1178-1181.

Castellucci, V. F., E. R. Kandel, J. H. Schwartz, F. D. Wilson, A. C.
Nairn, and P. Greengard (1980) Intracellular injection of the catalytic subunit of cyclic AMP-dependent protein kinase simulates facilitation of transmitter release underlying behavioral sensitization in Aplysia. Proc. Natl. Acad. Sci. USA 77: 7492-7496.

Castellucci, V. F., A. Nairn, P. Greengard, J. H. Schwartz, and E. R. Kandel (1982) Inhibitor of adenosine $3^{\prime}: 5^{\prime}$-monophosphate-dependent protein kinase blocks presynaptic facilitation in Aplysia. J. Neurosci. 2: 1673-1681.

Conti, M. A., and R. S. Adelstein (1980) Phosphorylation by cyclic adenosine $3^{\prime}-5^{\prime}$-monophosphate-dependent protein kinase regulates myosin light chain kinase. Fed. Proc. 39: 1569-1573.

Cooke, I. M., and M. W. Goldstone (1970) Fluorescence localization of monoamines in crab neurosecretory structures. J. Exp. Biol. 53: $651-668$.

Dixon, D., and H. L. Atwood (1985) Crayfish motor nerve terminal's response to serotonin examined by intracellular microelectrode. J. Neurobiol. 16: 409-424.

Dixon, D., and H. C. Atwood (1987) A role for both cAMP and phosphatidyl inositol in serotonin facilitation in crayfish. Soc. Neurosci. Abstr. 17: 596.

Drummond, A. H., J. A. Benson, and I. B. Levitan (1980) Serotonininduced hyperpolarization of an identified Aplysia neuron is mediated by cyclic AMP. Proc. Natl. Acad. Sci. USA 77: 5013-5017.

Dubey, M. P., R. C. Srimal, S. Nityanano, and B. N. Dhawan (1981) Pharmacological studies on coleonol, a hypotensive diterpine from Coleus forskohlii. J. Fthnopharmacol. 3: 1-13.

Dudel, J. (1965) Facilitatory effects of 5-hydroxytryptamine on the crayfish neuromuscular junction. Naunyn Schmiedeberg's Arch. Pharmacol. 249: 515-528.

Dunwiddie, T. V., and B. J. Hoffer (1982) The role of cyclic nucleotides in the nervous system. In Handbook of Experimental Pharmacology, Vol. 58, Pt. 2, J. W. Kebabian and J. W. Nathanson, eds., pp. 389463, Springer-Verlag, Berlin.

Enyeart, J. (1981) Cyclic AMP, 5-HT, and the modulation of transmitter release at the crayfish neuromuscular junction. J. Neurobiol. 12: 505-513.

Evans, P. D. (1984) The role of cyclic nucleotides and calcium in the mediation of the modulatory effects of octopamine on locust skeletal muscle. J. Physiol. (Lond.) 348: 325-340.

Florey, E., and E. Florey (1954) Uber die mogliche Bedeutung von Enteramin (5-oxytryptamin) als nervoser Aktimssubstanz bei cephalopoden und dekapoden Crustacean. Z. Naturforsch. 96: 58-68.

Fujiwara, M., and M. Kobayashi (1983) Modulation of neuromuscular transmission by serotonin in the molluscan radular muscles: Involvement of cyclic nucleotides. Comp. Biochem. Physiol. 75C: 239-246.

Gerschenfeld, H. M., and D. Paupardin-Tritsch (1974) On the transmitter function of 5-hydroxytryptamine at excitatory and inhibitory monosynaptic junctions. J. Physiol. (Lond.) 243: 457-481.

Glusman, S., and E. A. Kravitz (1982) The action of serotonin on excitatory nerve terminals in lobster nerve-muscle preparations. $J$. Physiol. (Lond.) 325: 223-241.

Goy, M. F., T. L. Schwarz, and E. A. Kravitz (1984) Serotonin-induced protein phosphorylation in a lobster neuromuscular preparation. $J$. Neurosci. 4: 611-626.

Greengard, P. (1976) Possible role for cyclic nucleotides and phosphorylated membrane proteins in postsynaptic actions of neurotransmittcrs. Naturc 260: 101-108.

Grundfest, H., and J. P. Reuben (1961) Neuromuscular synaptic activity in lobster. In Nervous Inhibition, E. Florey, ed., pp. 92-104, Pergamon, New York.

Kameyama, M., F. Hofmann, and W. Trautwein (1985) On the mechanism of $\beta$-adrenergic regulation of the $\mathrm{Ca}$ channel in the guinea pig heart. Pfluegers Arch. 405: 285-293.

Kandel, E. R., and J. H. Schwartz (1982) Molecular biology of learning: Modulation of transmitter release. Science 218: 433-443.

Kawagoe, R. K., K. Onodera, and A. Takeuchi (1982) On the quantal release of endogenous glutamate from the crayfish neuromuscular junction. J. Physiol. (Lond.) 322: 529-539.

Kerrick, W. G. L., and P. E. Hoar (1981) Inhibition of smooth muscle tension by cyclic AMP-dependent protein kinase. Nature 292: 253255.

Klein, M., and E. R. Kandel (1978) Presynaptic modulation of voltagedependent $\mathrm{Ca}^{2+}$ current: Mechanism for behavioral sensitization in Aplysia californica. Proc. Natl. Acad. Sci. USA 75: 3512-3516.

Klein, M., and E. R. Kandel (1980) Mechanism of calcium current 
modulation underlying presynaptic facilitation and behavioral sensitization in Aplysia. Proc. Natl. Acad. Sci. USA 77: 6912-6916.

Kohler, G., and T. Lindl (1980) Effects of 5-hydroxytryptamine, dopamine, and acetylcholine on accumulation of cyclic AMP and cyclic GMP in the anterior byssus retractor muscle of Mytilus edulis. Pfluegers Arch. 383: 257-262.

Kravitz, E. A., C. R. Slater, K. Takahashi, M. D. Bownds, and R. M. Grossfeld (1970) Excitatory transmission in invertebrates-glutamate as a potential neuromuscular transmitter compound. In Excitatory Synaptic Mechanisms, P. Anderson and J. K. S. Jansen, eds., pp. 85-93, Universitetsforlagel, Oslo.

Kravitz, E. A., S. Glusman, R. M. Harris-Warrick, M. S. Livingstone, T. Schwarz, and M. Goy (1980) Amines and a peptide as neurohormones in lobsters: Actions on neuromuscular preparations and preliminary behavioral studies. J. Exp. Biol. 89: 159-175.

Kravitz, E. A., B. S. Beltz, S. Glusman, M. F. Goy, R. M. HarrisWarrick, M. F. Johnston, M. S. Livingstone, T. L. Schwarz, and K. K. Siwicki (1985) The well-modulated lobster: The roles of serotonin, octopamine, and proctolin in the lobster nervous system. In Model Neural Networks and Behavior, A. I. Selverston, ed., pp. 339 360, Plenum, New York.

Kristan, W. B. J., and J. C. Weeks (1983) Neurons controlling the initiation, generation, and modulation of leech swimming. Soc. Exp. Biol. Symp. 37: 243-260.

Labrie, F., P. Borgeat, J. Drouin, L. Lagace, V. Giguere, V. Raymond, J. Godbout, and L. Massicotte (1982) The role of cyclic nucleotides in the control of anterior pituitary gland activity. In Handbook of Experimental Pharmacology, Vol. 58, Pt. 2, J. W. Kebabian and J. A. Nathanson, eds., pp. 525-566, Springer-Verlag, Berlin.

Lindner, E., A. N. Dchadwalla, and B. K. Bhattacharya (1978) Positive inotropic and blood pressure lowering activity of a diterpine isolated from Coleus forskohli: Forskolin. Arzneim. Forsch. 28: 284-289.

Livingstone, M. S., R. M. Harris-Warrick, and E. A. Kravitz (1980) Serotonin and octopamine produce opposite postures in lobsters. Science 208: 76-79.

Livingstone, M. S., S. F. Schaeffer, and E. A. Kravitz (1981) Biochemistry and ultrastructure of serotonergic nerve endings in the lobster: Serotonin and octopamine are contained in different nerve endings. J. Neurobiol. 12: 27-54

Lowry, O. H., N. J. Rosebrough, A. L. Farr, and R. J. Randall (1951) Protein measurement with the Folin phenol reagent. J. Biol. Chem. 193: 265-275.

Maynard, D. M., and J. H. Welsh (1959) Neurohormones of the pericardial organs of brachyuran Crustacea. J. Physiol. (Lond.) 149: 215 227.

Osterrieder, W., G. Brum, J. Hescheler, W. Trautwein, V. Flockerzi, and F. Hofmann (1982) Injection of subunits of cyclic AMP-dependent protein kinase into cardiac myocytes modulates $\mathrm{Ca}^{2+}$ current. Nature 298: 576-578.

Otsuka, M., L. L. Iversen, Z. W. Hall, and E. A. Kravitz (1966) Release of gamma-aminobutyric acid from inhibitory nerves in lobster. Proc. Natl. Acad. Sci. USA 56: 1110-1115.

Reuter, H. (1983) Calcium channel modulation by neurotransmitters, enzymes and drugs. Nature 301: 569-574.

Richardson, B. P., G. Engel, P. Donatsch, and P. A. Stadler (1985) Identification of serotonin M-receptor subtypes and their specific blockade by a new class of drugs. Nature 316: 126-131.

Rodger, I. W., and W. C. Bowman (1983) Adrenoceptors in skeletal muscle. In Adrenoceptors and Catecholamine Action, Part B, G. Kunos, ed., pp. 123-155, Wiley, New York.

Seamon, K. B., and J. W. Daley (1983) Forskolin, cyclic AMP, and cellular physiology. Trends Pharm. Sci. 4: 120-123.

Siegelbaum, S. A., J. S. Camardo, and E. R. Kandel (1982) Serotonin and cyclic AMP close single $\mathrm{K}^{+}$channels in Aplysia sensory neurons. Nature 299: 413-417.

Sullivan, R. E. (1978) Stimulus-coupled serotonin release from identified neurosecretory fibers in the spiny lobster, Panulirus interruptus. Life Sci. 22: 1429-1437.

Sullivan, R. E., B. J. Friend, and D. L. Barker (1977) Structure and function of spiny lobster ligamental nerve plexuses: Evidence for synthesis, storage and secretion of biogenic amines. J. Neurobiol. 8: 581605.

Takeuchi, A., and N. Takeuchi (1965) Localized action of gammaaminobutyric acid on the crayfish muscle. J. Physiol. (Lond.) 177 . 225-238.

Tsien, R. W. (1977) Cyclic AMP and contractile activity in heart. Adv. Cyclic Nucleotide Res. 8: 363-420.

Twarog, B. M. (1960) Effects of acetylcholine and 5-hydroxytryptamine on the contraction of a molluscan smooth muscle. J. Physiol. (Lond.) 152: 236-242.

Vanhoutte, P. M. (1985) Peripheral serotonergic receptors and hypertension. In Serotonin and the Cardiovascular System, P. M. Vanhoutte, ed., pp. 123-134, Raven, New York.

Weiner, N. (1979) Multiple factors regulating the release of norepinephrine consequent to nerve stimulation. Fed. Proc. 38: 2193-2202.

Weirsma, C. A. G., and S. H. Ripley (1952) Innervation patterns of crustacean limbs. Physiol. Comparata Oecol. 2: 391-405.

Weiss, K. R., J. L. Cohen, and I. Kupfermann (1978) Modulatory control of buccal musculature by a serotonergic neuron (metacerebral cell) in Aplysia. J. Neurophys. 41: 181-203.

Weiss, K. R., D. R. Mandelbaum, M. Schonberg, and I. Kupfermann (1979) Modulation of buccal muscle contractility by serotonergic metacerebral cells in Aplysia: Evidence for a role of cyclic adenosine monophosphate. J. Neurophys. 42: 791-803.

Welsh, J. H., and M. Moorhead (1960) The quantitative distribution of 5-hydroxytryptamine in the invertebrates, especially in their nervous systems. J. Neurochem. 6: 146-169.

Wheal, H. V., and G. A. Kerkut (1976) The pre- and post-synaptic actions of 5HT in Crustacea. Comp. Biochem. Physiol. 54C: 67-70. 